\title{
Style as Substance: Literary Ink Painting and Buddhist Practice in Late Ming Dynasty China
}

\author{
Kathleen M. Ryor
}

Many scholars of religion have studied the so-called Buddhist revival of the late Ming dynasty in China (mid-sixteenth to mid-seventeenth century) and have examined in great depth the syncretic nature of Buddhist doctrine and practice at this time. Correspondingly, art historians have noted a parallel resurgence in Buddhist figure painting by artists who also made a name for themselves depicting secular subjects. They have made a distinction in late Ming art between Buddhist paintings done often by anonymous artists for temples and monasteries, and scrolls executed by well-known artists, who were either themselves members of the literati or were patronized by this educated elite stratum of Chinese society. While art historians have noted this renewed interest in Buddhist figure painting among literati and literati-style painters starting around the last half of the sixteenth century, few have investigated the specific contexts for its production. With some exceptions in recent years, they have also tended to study these works in isolation from the artists' personal religious practices and beliefs. ${ }^{1}$ In contrast to paintings and sculptures in temples, the production of Buddhist ink paintings reflects what could be termed an environment of domestic devotion, as both the execution and viewing of such works took place in the private realm of the home rather than the more public space of the temple. This essay will also investigate the ways in which artists' doctrinal affinities influenced the subject and style of their Buddhist paintings. It will argue that different types of Buddhist traditions and iconography, and study and devotion to particular texts and deities, all influenced individual artists' depictions of Buddhist subject matter. In addition, the essay will suggest that artists' choice of painting style was not merely replicating pre-existing

1 For recent scholarship that investigates the links between an artist's personal religious practice and his painting of Buddhist subject matter, see Kent R.K., "Worldly Guardians of the Buddhist Law - Ding Yunpeng's Baimiao Luohans: A Reflection of Late Ming Lay Buddhism", Record of the Princeton University Art Museum 63 (2004) 62-89; Chen Y., "Wu Bin hua Ershiwu Yuantong ce [Research on Wu Bin's The Twenty Five Great Deities of the Surangama Sutra]", Meishushi jikan 13 (2002) 69-90; and Lo H.-C., "Shifting Identities in Wu Bin's Album of the Twenty-Five Dharma Gates of Perfect Wisdom”, Archives of Asian Art 66, 1 (2016) 107-151.

(C) KATHLEEN M. RYOR, 2019 | DOI:10.1163/9789004375888_014

This is an open access chapter distributed under the terms of the prevailing CC-BY-NC-ND License at the time of publication. 
artistic traditions, but was deployed mindfully to express Buddhist concepts and facilitate a variety of individual Buddhist devotional practices.

\section{Chan Revival and Chan Style Painting by Literati in the Late Ming}

Much recent scholarship on Buddhism during the Ming dynasty has been devoted to the relationship between the educated elite and state patronage and control of Buddhist institutions. This work has demonstrated that Buddhism declined after the early Ming dynasty (late fourteenth to early fifteenth century) as the result of several factors. ${ }^{2}$ The first Ming emperor, Zhu Yuanzhang (1328-1398), instituted a series of reforms that disrupted institutional structures handed down from the earlier Song (960-1279) and Yuan (1279-1368) dynasties. His successors continued this policy, and in the early fifteenth century turned their patronage exclusively to Tibetan Buddhism. During the first half of the sixteenth century, the Jiajing emperor (r. 1522-1566) favoured Daoism and attempted to suppress all Buddhist institutions; the state closed many temples, confiscated their property, and even went so far as to outlaw the ordination of monks in 1544. In addition, pirate raids in the 1550 s destroyed many Buddhist monasteries in south-eastern China. ${ }^{3}$ Communications between Buddhist communities and the social elite also dwindled significantly during the fifteenth and early sixteenth centuries. ${ }^{4}$

Historically, many different schools of Buddhism found adherents among the literati, but the school most intimately associated with the educated elite was Chan 禪 (Japanese name, Zen). In Chan Buddhism, ultimate reality is not a transcendental realm, but is equal to the daily world of relative reality, and every living being has the potential to realize enlightenment. The Chan practice

2 For more recent monographic studies of Buddhism during the late Ming dynasties, see Brook T., Praying for Power: Buddhism and the Formation of Gentry Society in Late Ming China (Cambridge: 1993); Wu J., Enlightenment in Dispute: The Reinvention of Chan Buddhism in Seventeenth Century China (Oxford - New York: 2008); McGuire B.F., Living Karma: The Religious Practices of Ouyi Zhixu (New York: 2014); Eichman J.L., A Late Sixteenth Century Chinese Buddhist Fellowship: Spiritual Ambitions, Intellectual Debates, and Epistolary Connections (Leiden: 2016).

3 For the impact of the wokou pirate raids on south-eastern China in the middle of the sixteenth century, see So K., Japanese Piracy in Ming China during the Sixteenth Century (East Lansing: 1975); Liang X., Wokou zhanzheng quanshi (Beijing: 2015).

4 Brook found that the exchange of poems between monks and literati in Nanjing dwindled to almost nothing after the early Ming period and that at the beginning of the sixteenth century the number of poems increased sharply. Brook, Praying for Power 94-95. See also Wu, Enlightenment in Dispute 22-24. 
of meditation stresses letting go of conceptual thinking and of the logical way in which we order the world, so that the appropriate insight and response arise naturally and spontaneously in the mind. Moreover, Chan Buddhism asserts that the concentrated mind can be achieved while doing so-called mundane tasks ranging from sweeping the floor to practicing calligraphy and painting. As a result, the goal of the Chan practitioner is to achieve a focused mind in all daily activities, in contrast to other forms of Buddhism in which rituals performed in a temple are considered most important for spiritual progress. In this way, Chan Buddhism, as experienced by lay practitioners, was almost exclusively a form of domestic devotion.

Although there were no eminent Chan masters in the Chinese monastic world during the fifteenth and early sixteenth centuries, a group of literati active in eastern Zhejiang province, largely comprised of the major disciples of the Neo-Confucian philosopher Wang Yangming (1472-1529), invited their favourite monks who followed Chan to their intellectual circles. ${ }^{5}$ As the work of Wu Jiang has shown, these literati who followed Wang's School of the Mind philosophy played a key role in reviving Chan and were particularly concerned about unqualified dharma transmission, a system that historically established a disciple as a successor to his master in an unbroken spiritual bloodline. $\mathrm{Wu}$ characterizes the interactions between literati and Chan monks as a reversed relationship in which the literati felt that they were qualified to judge the level of spiritual attainment of these monks. Thus, monks had to resort to these literati to gain insights into their own religion, in essence placing the literati in the position of master. ${ }^{6}$ For example, Wang Yangming had a close relationship with one Chan monk, Yuzhi Faju (1492-1563), but evidence shows that Faju was only an ordinary unaffiliated monk without any sign of distinction in his Buddhist practice and who was actually greatly inspired by Wang Yangming and became an intimate of several of his disciples. ${ }^{7}$

Among all scriptures with close intellectual ties to Chan Buddhism, the most popular one on which the literati chose to comment was the Shurangama Sutra. The study of the Shurangama Sutra had a long scholastic tradition in Buddhist monasteries dating back to the Song dynasty. While exegeses of this text had been popular during the eleventh to thirteenth centuries, the number

$5 \mathrm{Wu}$, Enlightenment in Dispute 72.

6 Wu, Enlightenment in Dispute 68.

7 Wu cites Araki Kengo's work on Yuzhi Faju in which he suggests that Faju later became a Chan monk who consciously introduced Wang's teaching of innate goodness into Chan Buddhism. See Wu, Enlightenment in Dispute 68. 
of commentaries written by literati during the sixteenth and seventeenth centuries far surpassed those of previous periods. ${ }^{8}$ The popularity of this scripture in the late Ming dynasty lay in the fact that it discusses the relationship between knowledge and action, a pivotal issue for the Confucian literati, especially for Wang Yangming and his followers. ${ }^{9}$ The sutra is primarily a dialogue between the Buddha and his cousin and disciple, Ananda. The circumstances that led to the Buddha's teaching found in the sutra revolve around a courtesan's nearly successful attempt to seduce Ananda and break his vow of celibacy. Ananda is mortified by his error and seeks instruction from the Buddha. The Buddha explains that his error was not merely the jeopardizing of his celibacy, but ultimately his laxity in his practice of meditation and deeper mental concentration (samadhi). ${ }^{10}$ Many important themes of Mahayana philosophy, such as the relationship between gradual cultivation and sudden enlightenment, and Buddhist cosmology and meditation, are discussed. The literati were particularly attracted to the Shurangama Sutra because it articulated their intellectual concerns over self-cultivation. Since literati excelled in learning, it was easy to identify themselves with Ananda, the main protagonist in the sutra, because he was the most knowledgeable person among the Buddha's disciples. Yet Ananda had difficulties with his moral cultivation. ${ }^{11}$ The Buddha observed that while Ananda had the keenest memory and highest level of learning among his disciples, he neglected genuine practice and cultivation because he relied solely on his intelligence and special relationship with the Buddha. ${ }^{12}$

Not only did literati study and write commentaries on the Shurangama Sutra and other texts associated with the study and practice of Chan Buddhism, but they also produced paintings of Buddhist subjects. In the earlier Song dynasty, Chan discourse on spontaneity influenced literati critics' analysis of artistic production. In a Chan context in which mental discipline is emphasized, it is natural that writers also addressed the question of concentration in the art of painting. ${ }^{13}$ In Chan painting of the Song dynasty, artists employed the

$8 \quad$ Wu, Enlightenment in Dispute $25^{-26 .}$

9 Wu, Enlightenment in Dispute 59-6o.

10 The term samadhi means the correct mental concentration that is necessary to deeper meditative states. It also indicates the deeper levels of mental concentration that can be reached through correct practice. For a discussion of how the term is used in the Shurangama Sutra, see Buddhist Text Translation Society, The Shurangama Sutra: With Excerpts from the Commentary by the Venerable Master Hsüan Hua (Ukiah, CA: 2009) xiv.

11 Wu, Enlightenment in Dispute 59-6o.

12 Buddhist Text Translation Society, The Shurangama Sutra xxviii.

13 Ortiz V.M., Dreaming the Southern Song Landscape: The Power of Illusion in Chinese Painting (Leiden: 1999) $15^{2}$. 
technique known as 'abbreviated strokes' (jianbi 減筆). In this style, all nonessential brushstrokes in a painting were eliminated, as in the cursive form of calligraphy. This can be seen in an anonymous Song dynasty work depicting a Chan Buddhist master [Fig. 12.1]; even though the painting is very abbreviated, the painter's brushwork displays extreme discipline. Each line delineates form, suggests volume, and implies motion, creating an image of intense concentration and rapid execution. ${ }^{14}$

By the Ming dynasty, although naturalness and spontaneity continued as acclaimed ideals in art criticism, the specific style of painting that had arisen out of these ideals associated with Chan in the Song period came to be condemned by scholars as unrestrained and wild. Beginning in the thirteenth century, critics thought that the dramatic treatment of ink was too unorthodox and too far from the traditional laws of brush technique. For the scholar-artists of the literati class, a renewed orthodoxy translated into the disciplined calligraphic brushwork that had been advocated since the sixth century; hence they found the free mode of Chan Buddhist painting too crude and called it vulgar. ${ }^{15}$ The general literati consensus was to value 'bone structure' (line and brushstroke) more than ink tones, and to place the brush at a higher qualitative level, because individual brushstrokes were said to reflect the character of the artist. While James Cahill has written about the persistence of what he termed 'Chan ink painting type images' into the Ming and Qing dynasties, his examination of this style of painting is fundamentally concerned with aesthetic issues of quality and disregards the context for the production of such works, as well as the meaning that both style and subject matter might express. ${ }^{16}$ I would like to suggest that the persistence of the Chan painting style into the late Ming dynasty was connected with the religious function of the works within the private or domestic sphere.

Even though the literati criticized the style of Chan painting, some professional painters of the Ming period continued to employ strong contrasts in ink and strong, abbreviated brushwork in figure paintings of religious subjects, particularly Daoist deities. Around the middle of the sixteenth century some literati artists also turned to this style for Buddhist subjects. In a depiction

\footnotetext{
14 Ortiz, Dreaming the Southern Song Landscape 145-146.

15 Ortiz, Dreaming the Southern Song Landscape 164.

16 Cahill J., "Continuations of Ch'an Ink Painitng in Ming-Ch'ing and the Prevalence of Type Images", Archives of Asian Art 50 (1997/1998) 17-41.
} 


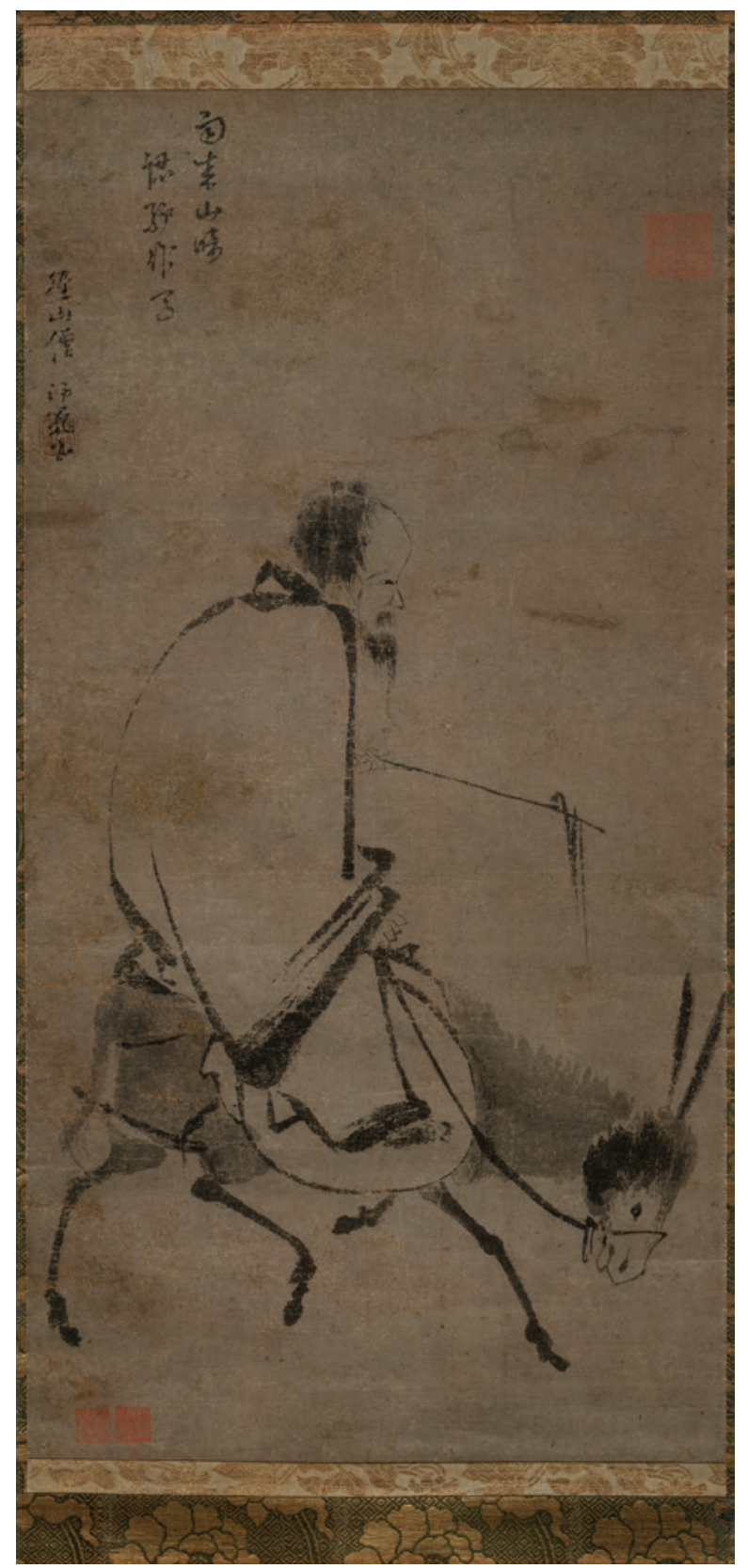

FIGURE 12.1 Anonymous, "Chan Master Riding a Mule"

(13th century). Hanging scroll, ink on paper,

$64.1 \times 33 \mathrm{~cm}$. New York, The Metropolitan

Museum of Art, Bequest of John M. Crawford, Jr., 1988 (1989.363.24). Image in the public domain 
of the Chan Buddhist figure Shide ${ }^{17}$ by Wang Wen (1497-1576) $)^{18}$ [Fig. 12.2], the painter deploys the bold and kinetic style originally associated with the eigth-century painting master $\mathrm{Wu}$ Daozi, ${ }^{19}$ and later with Chan Buddhist painters of the Song dynasty. As in thirteenth-century Chan works such as the painting reproduced at Fig. 12.1, there are a limited number of bold wet strokes and little detail. The gestural quality of the painting process is completely revealed. From extant sources it is difficult to discern the specifics of Wang Wen's personal religious practice within Chan; however, the case of his younger contemporary Xu Wei (1521-1593) demonstrates the connection between subject matter, choice of style, and Buddhist practice. Xu studied with two of Wang Yangming's major disciples and was a friend of the aforementioned Chan monk Yuzhi Faju, who had a close relationship with the philosopher. ${ }^{20}$ In a hanging scroll depicting one of numerous manifestations of the bodhisattva Guanyin [Fig. 12.3], ${ }^{21} \mathrm{Xu}$ Wei used the abbreviated brushwork method that derived from the tradition of gestural painting first used by Wu Daozi, who was noted for his intense concentration and rapid execution. In Chan terms, there is no distance between the mind and the brushstroke; in other words, immediacy and spontaneity could only emerge from an enlightened mind. Xu Wei's Lotus Boat Guanyin has a similar approach to the image of a Buddhist figure as Song dynasty Chan painting, in its simplification of form, strong contrast of ink tones, loose brushstrokes, and rapid execution [see Fig. 12.1]. The artist's inscription also underscores the concept of spontaneous enlightenment:

17 Shide is a legendary figure who is said to have lived at the Guoqing Temple on Mount Tiantai with his friends Hanshan and Fenggan during the ninth century. They were either low level or lay monks who performed menial tasks of labor. The three figures are images of Chan enlightenment.

18 Wang Wen was a literatus who obtained the highest civil service degree, the jinshi, in 1532. He served as an official in several government ministries, but retired from the civil service in 1554. For a brief biography of Wang Wen and his son Wang Jian, see Goodrich L.C. Fang C. (eds.), Dictionary of Ming Biography 1368-1644 (New York: 1976) 1444-1447.

19 Wu Daozi lived during the late seventh and early eighth centuries under the Tang dynasty and was a professional artist who specialized in Daoist and Buddhist figure painting. There are many apocryphal stories about his virtuosity, the most famous of which relates how when he put the last stroke in the pupil of a painting of a dragon, the dragon flew off of the wall and into the sky. No extant works by him survive. His painting style was noted for the expressive vigour of his brush which created lively calligraphic strokes that alternated between thick and thin.

20 Xu Wei studied with Ji Ben (1485-1563) and Wang Ji (1498-1583), both disciples of Wang Yangming. For Xu's biography of Yuzhi Faju, see Xu W., Xu Wei ji (Collected Writings of Xu Wei) (Beijing: 1983) 622-623.

21 Guanyin is the more commonly used term for Guanshiyin, which means the Bodhisattva Who Hears the Cries of the World. 


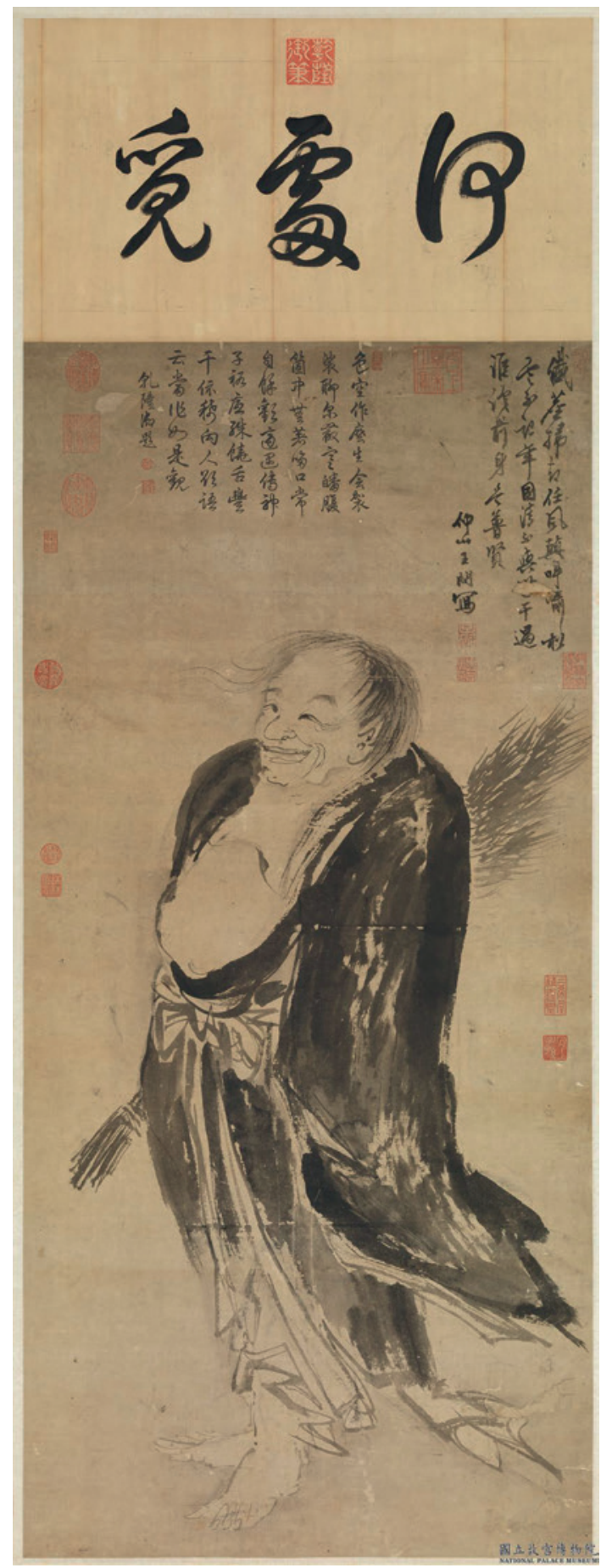

FIGURE 12.2

Wang Wen, "Shide Holding a Broom" (middle of the 16 th century). Hanging scroll, ink on paper, $117.8 \times 54.4 \mathrm{~cm}$. Taipei, National Palace Museum IMAGE (C) NATIONAL PALACE MUSEUM 


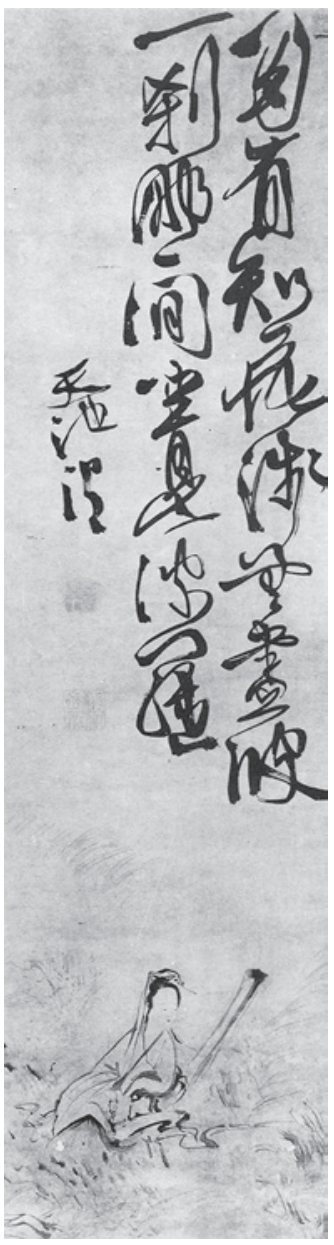

FIGURE 12.3

Xu Wei, "Lotus Boat Guanyin" (late 16th century). Hanging scroll, ink on paper, $116 \times 29.2 \mathrm{~cm}$. Beijing, National Art Gallery of China. Reproduced in Xu Wei hua ji (Hangzhou: 1991), 24

Illusion contains wisdom and awakening,

Passing through limitless waves;

In a nanosecond, sitting and seeing the paramita boat. ${ }^{22}$

The last line specifically references one of the most famous parables related by the Buddha. In it, he tells of a man who creates a makeshift raft in order to leave a dangerous place and get to the opposite shore of safety; once he has arrived at the other shore he abandons the raft. The Buddha used this story to illustrate

22 The term 波羅 is the Chinese translation of the Sanskrit paramita, 'one who has reached the other shore', and can refer to the title of the Buddha Who Has Reached the Other Shore (tathagata). 
that the practitioner will recognize the usefulness of the teachings (dharma) but not become attached to them once he has attained enlightenment.

$\mathrm{Xu}$ Wei was primarily a secular painter of flowers and plants, yet when he turned to Buddhist subjects he depicted the bodhisattva Guanyin almost exclusively. Bodhisattvas are beings who have attained the highest level of enlightenment, but who out of great compassion delay their entrance into Buddhahood in order to guide other sentient beings. Guanyin is the one of the most important bodhisattvas in Buddhism and can appear to the devotee in many different forms. For this reason, in China, devotion to the worship of Guanyin existed in many schools of Buddhism. In the sixth chapter of the Shurangama Sutra, after the twenty-five great deities explain how their spiritual practice allowed them to enter samadhi, it is Guanyin who is held up as the model for Ananda to emulate. Xu Wei felt that he had achieved a high level of understanding of the Shurangama Sutra. ${ }^{23}$ It also appears that this bodhisattva was of particular importance to Xu's Buddhist practice. ${ }^{24}$ In the inscription on another painting of Guanyin that is no longer extant, Xu Wei makes explicit the connection between the importance of this bodhisattva and the style in which one depicts her:

The mahasattva [or Great Bodhisattva] Guanyin,

Uses her ear to enter onto the path,

Thirty-two manifestations,

The gateway to salvation is not merely one.

This appearance of the bodhisattva

Is painted without using colour,

Resembling Wu Daozi,

I obtain stone in order to engrave it. ${ }^{25}$

The second stanza identifies Wu Daozi as the stylistic model, while the first stanza makes reference to the thirty-two or thirty-three manifestations of Guanyin described in the Shurangama Sutra, as well as other popular Buddhist texts such as the Lotus Sutra.

\footnotetext{
$23 \mathrm{Xu}$, Xu Weiji 639.

24 Xu Wei's collected writings have numerous poems and encomia that he composed for his paintings of Guanyin. He painted various manifestations of Guanyin, all in female form, such as the Fish Basket Guanyin/Wife of Mr. Ma, White-Robed Guanyin, Guanyin of the Southern Seas, Guanyin as an ugly old woman, etc. For a discussion of Guanyin's female forms, see Yü C., Kuan-yin: The Chinese Transformation of Avalokitesvara (New York: 2001). 
In a different inscription on a no longer extant Guanyin painting, Xu Wei articulates the relationship between artistic styles and specific sutras:

One Guanyin dharma, but there are two sutras that explicate it, The Lotus Sutra for other people's actions,

The Shurangama Sutra for one's own conduct;

Wenling and Gushan, ${ }^{26}$

Both perfected these two sutras.

There are two kinds of enlightened beings,

Painters are also like this;

One [kind] resembles [Wu] Daozi,

One [kind] resembles [Li] Longmian. ${ }^{27}$

Here Xu Wei again makes clear his association with the free, abbreviated style first ascribed to Wu Daozi and later developed by Chan artists with the Shurangama Sutra. In this inscription, he contrasts the controlled fine line style known as baimiao 白描, made famous by the eleventh-century lay Buddhist Li Gonglin - whose sobriquet was Longmian (1049-1106) ${ }^{28}$ - with that of Wu Daozi and the Chan painting tradition. That the style is part of his particular Buddhist practice is also evident in this stanza from one of five encomiums written on paintings of the different manifestations of Guanyin:

If I don't believe,

I inquire about it from Wu Daozi,

Then I begin to believe. ${ }^{29}$

26 Wenling is the Jiehuan, a Song dynasty monk and commentator on the Lotus Sutra, and Gushan probably refers to the monk Zhiyuan (976-1022), who wrote a commentary on the Shurangama Sutra.

$27 \mathrm{Xu}, \mathrm{Xu}$ Wei ji 580. Even though this translation implies that Wu's style is associated with the Lotus Sutra, the other texts by Xu Wei cited here clearly indicate that he associated Wu's style with Chan and the Shurangama Sutra.

28 Li Gonglin was born into a family of Confucian scholars and received the jinshi degree in 1070. He served as an official in several positions, and was renowned as a painter, antiquarian and connoisseur. He was also a very serious lay Buddhist who followed a syncretic form of Chan practised at a centre in the Longmian Mountains where his country villa was located.

$29 \mathrm{Xu}, \mathrm{Xu}$ Weiji 981. 
While the exact meaning of the verse is somewhat enigmatic, Xu suggests that somehow painting in the style of Wu Daozi has the power to further his religious beliefs.

$\mathrm{Xu}$ Wei thus painted images of Guanyin, whose method of attaining sama$d h i$ is seen as most efficacious in the Shurangama Sutra, in a style that requires control and focus, yet must be executed swiftly and spontaneously, qualities that visually approximate the notion of sudden enlightenment found in Chan Buddhism that was being revived in the sixteenth and seventeenth centuries. The invocation of legendary artistic masters of the past was a hackneyed convention within many late Ming contexts; however, when certain literati artists who were Buddhist devotees refer to Wu Daozi's (and Li Gonglin's) style specifically in the production of Buddhist subject matter, the choice of style becomes a form of Buddhist practice that embodies particular and personal modes of focusing the mind within a private space.

\section{Buddhist Syncretism During the Late Ming Period and the Baimiao} Revival

While some literati Chan practitioners chose to paint Buddhist subjects in a style that had been traditionally associated with Wu Daozi and Chan Buddhism from the Song dynasty, others turned to painting in the stylistic tradition of the scholar and lay Buddhist Li Gonglin. Li's linear style of monochrome ink, known as baimiao, was taken up by later Song painters such as the monk-painter Fanlong, one of Li Gonglin's direct disciples [Fig. 12.4]. ${ }^{30}$ For example, The Eighteen Luohans attributed to Fanlong presents the physical features of the figures in pale ink and even, thin lines. Whereas secular artists who followed Li Gonglin's style maintained a uniform ink tonality and thickness of brush line, Fanlong, and other monk-painters, modified this mode by reserving a very light ink treatment for certain parts of the figures, suggesting that a mysterious body is lodged in a mundane and real environment. ${ }^{31}$

This extremely fine line mode of painting was also a visual analogue to concentrated practice, which was not unique to any one Buddhist sect. The three well known Buddhist monk reformers of the late Ming dynasty, Zibo Zhenke (1543-1603), Hanshan Deqing (1546-1623), and Yunqi Zhuhong (1535-1615),

\footnotetext{
30 Fanlong (active middle of the twelfth century) was a follower of a style of Chan Buddhism practised at a centre in the Longmian Mountains that synthesized Huayan and Tiantai thought with Chan.

31 Ortiz, Dreaming the Southern Song Landscape 145.
} 


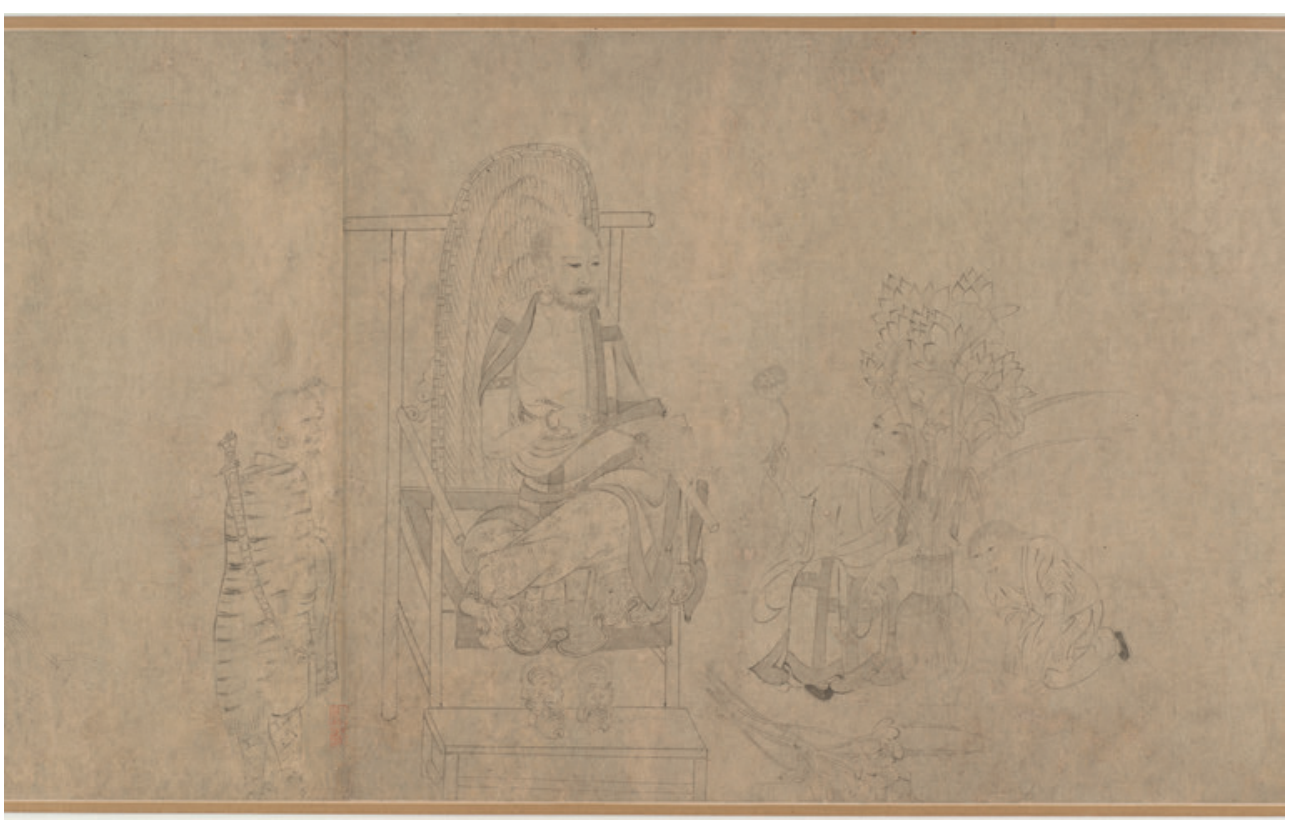

FIGURE 12.4 Fanlong, "The Eighteen Luohans" (middle of the 12th century). Handscroll, ink on paper, $30.5 \times 1062.5 \mathrm{~cm}$. Washington, D.C., Freer Gallery of Art, Purchase (F1960.1). Detail of section 4 IMAGE (C) FREER GALLERY OF ART

revived the system of monastic rules and regarded the practice of the Pure Land School of Buddhism as a remedy and correction to what they considered the unbalanced approach of Chan..$^{32}$ An emphasis on a disciplined method of spiritual cultivation was common to their teachings, rather than the mind to mind, dharma transmission found in Chan. ${ }^{33}$ This syncretic Buddhist revival among the literati towards the end of the sixteenth century, which merged the practices of Pure Land and other schools of Buddhism, coincided with a revival of baimiao painting of Buddhist subjects, particularly of luohans. As the work of Richard Kent has shown, the late Ming artist Ding Yunpeng (c. 15471628), the most prolific painter of Buddhist subjects of the time, had personal ties to both Deqing and Zhenke and used various terms for a lay Buddhist in

$32 \mathrm{Wu}$, Enlightenment in Dispute 63.

33 Jennifer Eichman has studied Zhuhong's critique of Chan and his promotion of a variety of practices that he argued had spiritual efficacy. See in particular, Eichman J., Spiritual Seekers in a Fluid Landscape: A Chinese Buddhist Network in the Wanli Period (1573-1620), Ph.D. dissertation (Princeton University: 2005) 169-194. 


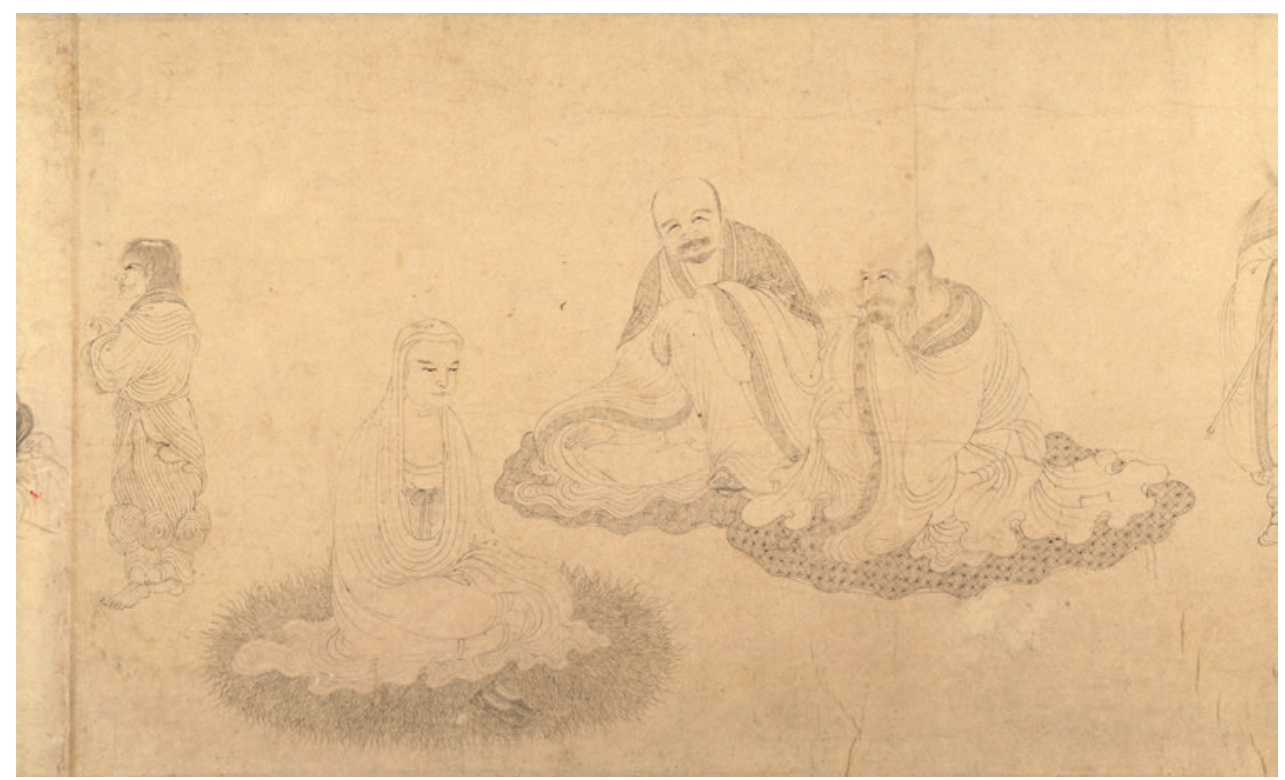

FIGURE 12.5 Ding Yunpeng, "Luohans" (1580). Handscroll, ink on paper, $26 \times 343.5 \mathrm{~cm}$. Princeton, Princeton University Art Museum, museum purchase Fowler McCormick, Class of 1921, Fund and gift of Lloyd E. Cotsen, Class of 1950, in honour of Wen C. Fong, Class of $195^{1}$ and Graduate School Class of $195^{8}$ (2001-182). Detail of the third quarter of the scroll IMAGE @ PRINCETON UNIVERSITY ART MUSEUM

his signature. ${ }^{34}$ In Chinese Buddhism, luohans are the original disciples of the Buddha who have reached the state of nirvana and are free from worldly cravings. They are charged to protect the Buddhist faith and await the coming of Maitreya, the enlightened Buddha prophesied to arrive on earth several millennia after the historical Buddha's death. They were exemplars because they had suffered afflictions, extinguished all defilements, and severed all bonds of existence and thus served as models of enlightenment for laypeople. Their iconography by the Ming dynasty had also absorbed imagery associated with Daoist immortals and other supernatural beings. Their popularity may thus have been related to the more worldly goals of cultivating virtue and attaining longevity.

Ding Yunpeng's choice of the baimiao style for his handscroll of luohans dated 1580 [Fig. 12.5] reflects an interest in slow and sustained attention to detail that is analogous to the disciplined practices advocated by Zhenke, Deqing and other late Ming monk reformers. Every single brushstroke in this painting

34 Kent, "Worldly Guardians of the Buddhist Law" 10. 


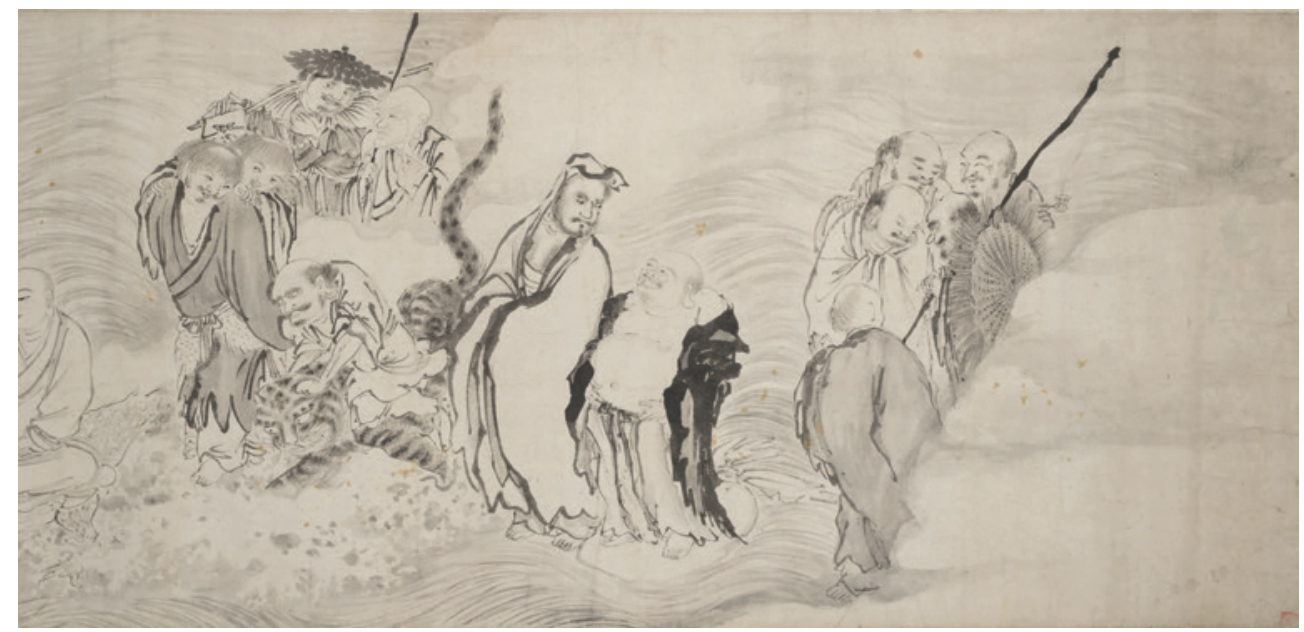

FIGURE 12.6 Wang Wen, "The Eighteen Luohans Crossing the Sea" (middle of the 16th century). Handscroll, ink on paper, $32.4 \times 138.4 \mathrm{~cm}$. Berkeley, Berkeley Art Museum and Pacific Film Archive. Gift of James and Dorothy Cahill (1986.35) IMAGE (C) BERKELEY ART MUSEUM

is extremely thin and delicate, and the line work in the border of the luohans' robes and their facial hair is nearly impossible to see with the naked eye. Ding produced many paintings of Buddhist subjects in this style, but despite making a living as a professional artist, there is very little evidence for specific patrons for these works. This suggests a private function to the paintings; the handscroll format in particular is one that is intimate in size and experience, since only an arms-width of the scroll would be unrolled at a time. As a result, it can only be viewed by a few people. The very illegibility of images executed in the baimiao style further suggests that a viewing audience for the painting may not be its primary purpose.

If we compare a section of Ding's luohans with Wang Wen's painting of the same subject [Fig. 12.6], we see how two different Ming artists choose one of the two modes of painting associated with Buddhism - the Wu Daozi tradition of bold calligraphic brushwork and abbreviation versus the pale fine lineation of the baimiao style of Li Gonglin. These stylistic choices represent each artist's own doctrinal affiliation and practice; Wang Wen with Chan, and Ding Yunpeng with the syncretic teachings of Deqing. In contrast to Ding's delicate pale lines of even thickness, Wang's style exhibits strong visual contrasts between the bold calligraphic brushwork of the figures' robes and the thinner lighter line used for the facial features. While not as abbreviated in style as 
his image of Shide [Fig. 12.2], this depiction of Buddhist figures nonetheless emphasizes the sketchy kinetic quality found in Chan painting. Wang Wen has even included Chan figures in his composition, with a grouping of the founder of Chan, Bodhidharma, as well as Budai, Hanshan, Shide and Fenggan, placed between groups of luohans. ${ }^{35}$

While Ding Yunpeng was the most prolific painter of Buddhist subjects in the baimiao mode, he was by no means the only artist who depicted this type of subject matter in this style. Wang Wen's son, Wang Jian (1520-1590), ${ }^{36}$ employed the baimiao style in several paintings of luohans, and the similarity in technique can be seen in his handscroll in the Minneapolis Institute of Arts [Fig. 12.7] depicting luohans crossing the sea. This theme symbolizes the luohans' role as agents of Buddhist salvation and their ability to enable others to cross over the sea of worldly delusions to reach the shore of liberation. ${ }^{37}$ The fine, controlled lines in monochrome ink are so pale that the scroll demands sustained close viewing for legibility. Like Ding's handscroll, concentration is needed for both the production and reading of the work. The contrast between Wang Jian's luohans and his father Wang Wen's painting of the same subject is quite striking. While the style that Wang Wen employs combines concentration with kinetic energy, his son's faint, painstakingly detailed brushwork reflects the same level of intense focus but results in an image that is both representationally accurate and harder to see. It is difficult to connect either Wang Wen or Wang Jian with a specific Buddhist practice or teacher at this point, but Wang Jian would certainly have heard of all three of the well-known monk reformers and likely would have had some type of interaction with them, considering the elite social circles in which he moved. He did at least one painting of luohans for a monk, providing evidence that he had close interactions with Buddhist clergy and that he was a serious lay Buddhist.

35 Bodhidharma was a Buddhist monk from Central Asia who came to China in the fifth century. He is traditionally regarded as the first patriarch of Chan Buddhism and was said to have established the Shaolin monastery on Mt Song. Budai was an eccentric Chan monk who lived in China during the tenth century and became identified with Maitreya, the Buddha of the Future.

36 This Wang Jian's name has the same characters as the much more famous early Qing dynasty painter who lived from $1598-1677$.

37 Kent R.K., "Depictions of the Guardians of the Law: Luohan Painting in China", in Weidner M. (ed.), Latter Days of the Law: Images of Chinese Buddhism 850-1850 (Lawrence, KS: 1994) 188. 


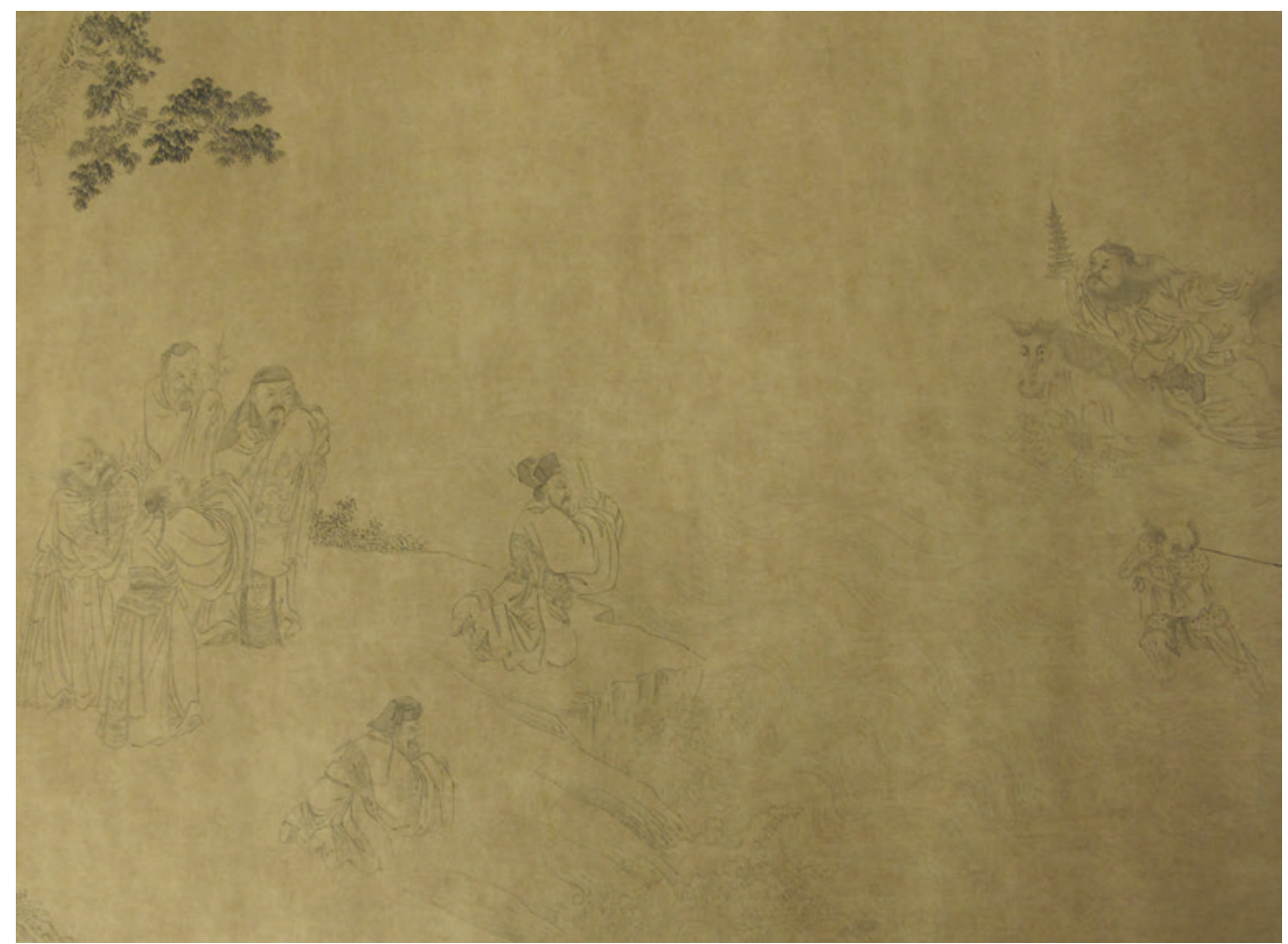

FIGURE 12.7 Wang Jian, "Luohans Crossing the Sea" (ca. 1580). Handscroll, ink on paper, $30.48 \times 425.45 \mathrm{~cm}$. Minneapolis, Minneapolis Institute of Arts, Gift of Ruth and Bruce Dayton (97.139.1). Detail of second to last section of the scroll. Image in the public domain

For lay Buddhist painters such as Ding Yunpeng, creating Buddhist art was more than just an artistic or professional activity, but a meditative exercise akin to the copying out of a sutra, a task performed to gain karmic merit through the state of mind that the practitioner brought to the endeavour. This use of the baimiao style, however, was not limited to those who followed the teachings of the monk reformers, nor to the depiction of luohans. During the Ming dynasty, the cult of Guanyin was popular among women devotees, particularly the manifestation of the White-Robed, Child-Giving Guanyin. Texts recount the stories of women and even some male worshippers who, after they had chanted related scriptures a thousand times, all miraculously brought a child into the world, usually a son. As Li Yuhang's work has shown, elite women 


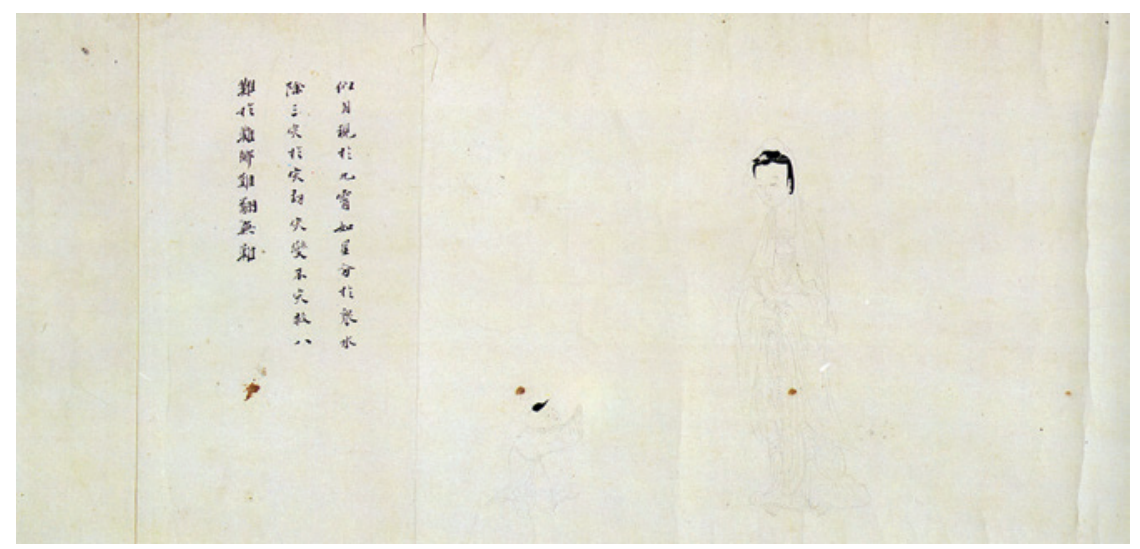

FIGURE 12.8 Xing Cijing, "Five White-Robed, Child-Giving Guanyins" (ca. 1614).

Handscroll, ink on paper, $30.3 \times 371.5 \mathrm{~cm}$. Qingdao, Qingdao Municipal Museum. Detail of section 3. Reproduced in Zhongguo gudai shuhua tumu (Beijing: 1986-2001), vol. 16, 299

of the period used the home as a space to practice Buddhism, and they also engaged in practices such as copying sutras and making paintings just as men did. Li has argued that the scroll of five images of the White-robed, Child-giving Guanyin by Xing Cijing (ca. 1570 - after 1640), sister of the famous calligrapher Xing Tong (1551-1612), was done at age 40 after the birth of her only child (a son) as a ritual act of gratitude [Fig. 12.8]. ${ }^{38}$ Li situates Xing within the milieu of educated women from elite families who devoted themselves to the cult of Guanyin. Her brother and his eldest son both copied images of, and sutras devoted to Guanyin in order to pray for male heirs. Li's study of Xing Cijing's scroll of five White-robed Guanyins emphasizes the content of the inscriptions as evidence for elite women's worship of the deity. I would also like to suggest that Xing's use of this very delicate and meticulous baimiao style for an image of Guanyin was chosen, as in the case of Ding Yunpeng's luohans, as a mode of disciplined practice that demonstrated her religious devotion to the bodhisattva and gratitude for Guanyin's magical efficacy in bringing her a son. Like Ding Yunpeng and Wang Jian, Xing Cijing's handscroll uses extremely delicate lines of pale ink to depict the figures; however, Xing's representation of each figure is somewhat more simplified in their level of detail and the solid black ink of the hair renders the face and body more indistinct by contrast. In this

38 Li Y., Gendered Materialization: An Investigation of Women's Artistic and Literary Reproductions of Guanyin in Late Imperial China, Ph.D. dissertation (University of Chicago: 2011) 43-56. 


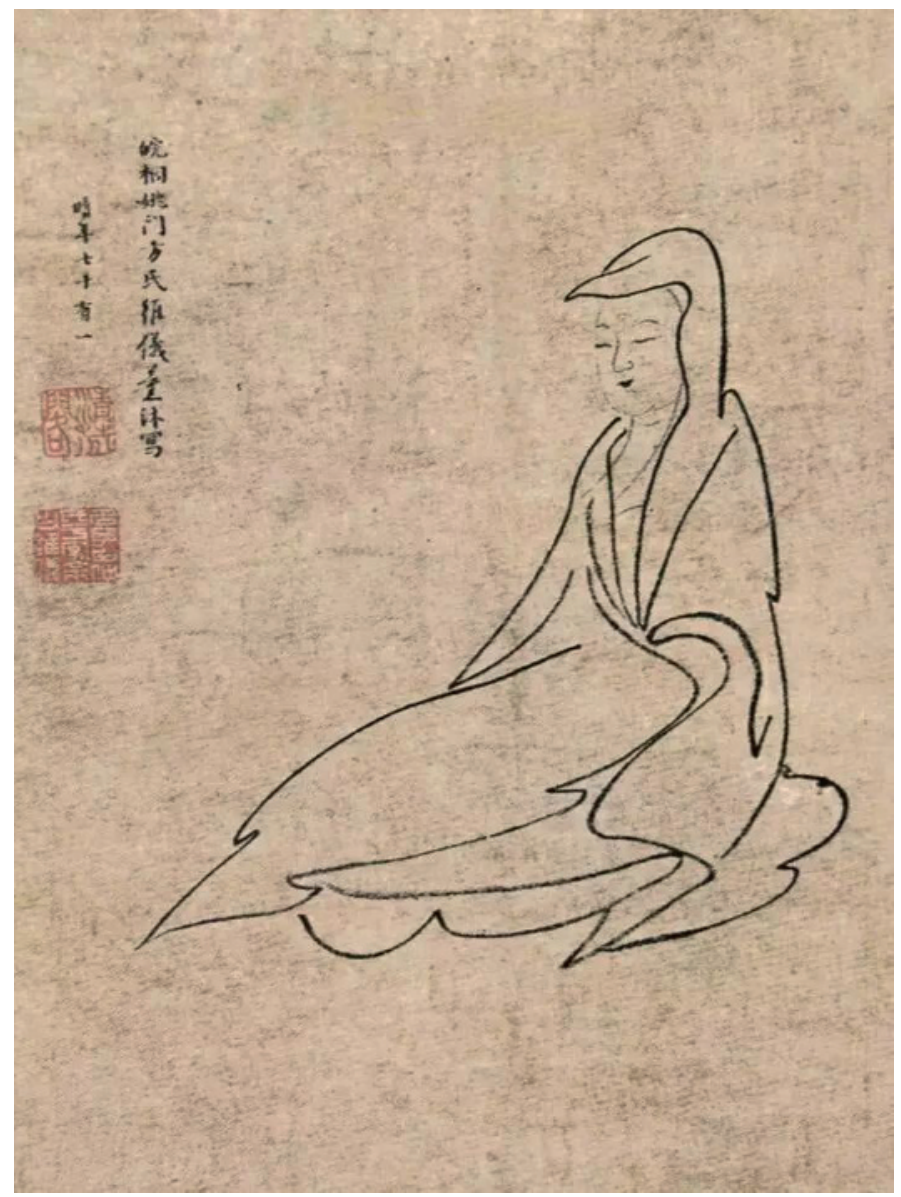

FIGURE 12.9 Fang Weiyi, "The White-Robed Guanyin" (1656). Hanging scroll, ink on paper, $56 \times 26.6 \mathrm{~cm}$. Beijing, Palace

Museum. Image in the public domain

case, Xing created the painting for a more specific spiritual goal in which her devotion to this particular deity is expressed through a disciplined material practice.

Li's other case study of the late Ming widow Fang Weiyi (1585-1668) analyses Fang's interest in creating images of Guanyin within the context of her practice of Chan Buddhism. Despite the integration of the cults of the Whiterobed Guanyin and the Child-giving Guanyin in this period, the White-robed Guanyin's earlier association with Chan Buddhism had not disappeared, as this form of the bodhisattva symbolized the serenity of Chan meditative 
states. ${ }^{39} \mathrm{~A}$ brief comparison of Fang's painting dated 1656 [Fig. 12.9] with Xing Cijing's work shows that Fang used the extremely abbreviated style of painting associated with Chan; moreover, like the literatus Xu Wei discussed earlier, she associated this mode of painting with the progenitor of this style, the eighthcentury artist Wu Daozi. ${ }^{40}$ Even though Xu Wei's work has a greater number of brush strokes and stronger tonal contrasts, both paintings depict the figure using long undulating strokes and create a strong contrast between the tiny faint lines in the face and the bolder more calligraphic strokes used in the clothing. Both Fang and Xu also make a specific connection in their writings between the concentration and immediacy of the Wu Daozi style and the Chan belief that immediacy and spontaneity in writing or painting emerge from the enlightened mind. While it is generally agreed that there were probably no genuine Wu Daozi paintings extant by the late Ming period, the understanding of this stylistic mode for the painting of Buddhist subject matter reflected a specific religious affiliation with Chan practices in contradistinction to the other style of figure painting traditionally associated with Buddhist subjects, baimiao. Baimiao, in fact, seems to have the wider semantic range since its practitioners in the late sixteenth and early seventeenth centuries were associated with diverse Buddhist devotional practices.

\section{$4 \quad$ Conclusion}

While this essay has set up a binary that contrasts a style associated with the legendary Tang figure painting master Wu Daozi, as filtered through the Chan Buddhist painting style of the Song dynasty, with the fine line style of painting known as baimiao, associated with the Song dynasty lay Buddhist literatus Li Gonglin, there were certainly other painting styles through which an individual artist's Buddhist practice was expressed. For example, Chen Yunu has demonstrated that the artist Wu Bin (active 1572-1620) viewed his painting of Buddhist subjects as a penitential ceremony, as well as a meditative act similar to sutra copying. Like other artists such as Ding Yunpeng, Wu indicated his devotion as a lay Buddhist in his various signatures, and was personally acquainted with Hanshan Deqing. ${ }^{41}$ In contrast to both the free Chan style and baimiao,

\footnotetext{
$39 \quad$ Li, Gendered Materialization 64.

40 Li Yuhang mentions that Fang said that, 'it was most difficult to [paint] the halo in a single stroke as Wu Daozi did'; see Li, Gendered Materialization 68-69.

41

Lo, "Shifting Identities" 109.
} 
Wu's style of Buddhist figure painting used brush strokes of even thickness to create images with areas of dense detail, but the outlines are thicker than those employed in the baimiao style. His paintings also use colour and display fantastic exaggeration of form.

This preliminary study has argued that the choice of painting style, as well as subject matter, in the production of Buddhist images by lay Buddhist literati of the late Ming dynasty may be related to religious practices of individuals within the private space of their residences and studios. It has also suggested that specific styles and the depiction of specific Buddhist figures may reflect the particular Buddhist doctrinal affinities and practices of each artist. The adoption of the abbreviated calligraphic style associated first with Wu Daozi and later employed by Chan monks of the Song dynasty is linked to the revival of Chan. This revival sought to re-establish mind to mind dharma transmission and retained the central notion of sudden enlightenment. The use of the pale and controlled fine line style of baimiao associated with the Song scholar and lay Buddhist Li Gonglin was a form of execution that reflected the ideas of reformist monks such as Hanshan Deqing, who advocated disciplined practices such as textual study and ritual chanting, and who were critical of what they viewed as the excesses of the Chan tradition. In addition, preference for certain subject matter may well have been connected to these artists' own religious practices. For example, the depiction of Guanyin was related in some cases specifically to the Chan promotion of the bodhisattva as the role model for meditation, and in others to the cult of the child-giving manifestation of the deity. There were also other styles employed by late Ming painters of Buddhist subjects, especially one that revived an archaistic mode of colour and line painting, and hopefully future research will start to reveal the complex ways in which painting played a role in the personal devotional practices of late Ming elite men and women.

\section{Bibliography}

Brook T., Praying for Power: Buddhism and the Formation of Gentry Society in Late Ming China (Cambridge: 1993).

Buddhist Text Translation Society, The Shurangama Sutra: With Excerpts from the Commentary by the Venerable Master Hsüan Hua (Ukiah, CA: 2009).

Cahill J., "Continuations of Ch'an Ink Painting in Ming-Ch'ing and the Prevalence of Type Images", Archives of Asian Art 50 (1997/1998) 17-41.

Eichman J.L., A Late Sixteenth Century Chinese Buddhist Fellowship: Spiritual Ambitions, Intellectual Debates, and Epistolary Connections (Leiden - Boston: 2016). 
Eichman J.L., Spiritual Seekers in a Fluid Landscape: A Chinese Buddhist Network in the Wanli Period (1573-1620), Ph.D. dissertation (Princeton University: 2005).

Goodrich L.C. - Fang C. (eds.), Dictionary of Ming Biography 1368-1644 (New York: 1976).

Kent R.K., "Depictions of the Guardians of the Law: Luohan Painting in China", in Weidner M. (ed.), Latter Days of the Law: Images of Chinese Buddhism 850-1850 (Lawrence, KS: 1994) 183-213.

Kent R.K., "Worldly Guardians of the Buddhist Law - Ding Yunpeng's Baimiao Luohans: A Reflection of Late Ming Lay Buddhism", Record of the Princeton University Art Museum 63 (2004) 62-89.

Li Y., Gendered Materialization: An Investigation of Women's Artistic and Literary Reproductions of Guanyin in Late Imperial China, Ph.D. dissertation (University of Chicago: 2011).

Lo H.-C., "Shifting Identities in Wu Bin's Album of the Twenty-Five Dharma Gates of Perfect Wisdom", Archives of Asian Art 66, 1 (2016) 107-51.

McGuire B.F., Living Karma: The Religious Practices of Ouyi Zhixu (New York: 2014).

Ortiz V.M., Dreaming the Southern Song Landscape: The Power of Illusion in Chinese Painting (Leiden - Boston: 1999).

Wu J., Enlightenment in Dispute: The Reinvention of Chan Buddhism in Seventeenth Century China (Oxford - New York: 2008).

Yü C., Kuan-yin: The Chinese Transformation of Avalokitesvara (New York: 2001).

Xu W., Xu Weiji (Beijing: 1983). 